\title{
Dopaminergic Modulation of Afferent Synaptic Transmission in the Semicircular Canals of Frogs
}

\author{
G.N. Andrianov I.V. Ryzhova T.V. Tobias \\ Pavlov Institute of Physiology of the Russian Academy of Sciences, St. Petersburg, Russia
}

\section{Key Words}

Glutamate receptors - Neurotransmitters ·

Neuromodulators $\cdot$ Dopamine $\cdot$ Afferent synapse $\cdot$

Vestibular apparatus

\begin{abstract}
Using multiunit recording of action potentials from the whole nerve with the aid of external perfusion, we investigated the effects of dopamine (DOP) agonists that are involved in modulatory actions on synaptic transmission in the isolated labyrinth preparations of frogs. The external application of DOP (0.1-1 mM), the $D_{1}$ agonist chloro-APB hydrobromide (CAPB, 50-100 $\mu \mathrm{M}$ ) and the $\mathrm{D}_{2}$ agonist quinerolane (QUI, 50-100 $\mu \mathrm{M}$ ) induced a dose-dependent and reversible decline in the resting discharge frequency. In this concentration range, the potency of applied CAPB considerably exceeded that of QUI. AMPA, NMDA and ACPD responses were inhibited by the $D_{1}$ and $D_{2}$ agonists, implicating both subtypes of DOP receptors in the modulation of both ionotropic and metabotropic glutamate receptors. The inhibitory action of the DOP agonists on L-glutamate responses persisted in a high $\mathrm{Mg}^{2+}$ solution in conditions of selective activation of the postsynaptic membrane. The results obtained suggest that DOP may interact with both $D_{1}$ and $D_{2}$ receptor subtypes, most likely located postsynaptically on
\end{abstract}

the afferent nerve fibers. This dopaminergic control mechanism may result in the reduction of the activated firing rate, thus preventing over-excitation and excitotoxic injury of the afferent dendrites after the external application of L-glutamate and excessive receptor stimulation.

Copyright $\odot 2009$ S. Karger AG, Basel

\section{Introduction}

Throughout the vestibular organs of vertebrates, the sensory receptors are hair cells, which are considered to be secondary sense cells that transmit synaptically to the afferent nerve fibers. Transmission at this synapse is chemically mediated. L-Glutamate (L-Glu) is thought to be the major excitatory neurotransmitter in the peripheral portion of the vestibular system of vertebrates and acts on multiple receptor types. The actions of L-Glu are mediated both by ionotropic receptors, which form ion channels, and metabotropic glutamate receptors coupled by $G$ proteins to various second messengers. The latter are directly coupled with effector systems via GTP-binding proteins and are thought to modulate synaptic transmission [1-3].

It is generally accepted that communication between hair cells and afferent nerve fibers is regulated by neu-

G.N. Andrianov

Pavlov Institute of Physiology of the Russian Academy of Sciences

Nab. Makarova 6

St. Petersburg 199034 (Russia)

Tel. +7 812328 1676, ext. 139, Fax +7 812328 0501, E-Mail andryu@infran.ru 


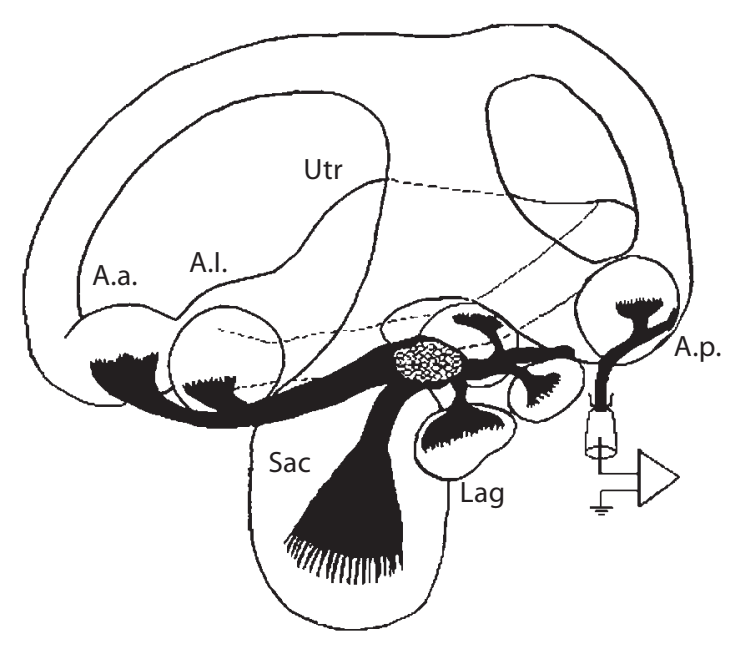

Fig. 1. Schematic drawing of the experimental setup used for recording multiunit resting activity of the semicircular canal nerve in the isolated inner ear preparation of the frog. The posterior canal ampullar nerve was sucked into a glass pipette filled with Ringer solution and connected to an AC amplifier, an oscilloscope and a laboratory computer. Utr = Utricle; Sac = saccule; Lag = lagena; A.a., A.l., A.p. = ampullae anterior, lateral and posterior, respectively.

romodulator substances that may modify the action of the neurotransmitters. Many substances, including opioid peptides [3-8], calcitonin gene-related peptide, GABA, histamine, taurine, substance $P$ and others $[1-3$, 9] have been proposed as potential neuromodulator candidates. Recent studies extended the evidence for the involvement of metabotropic glutamate receptors in modulation of excitatory neurotransmission at the afferent hair cell synapses in the vestibular organs of frogs $[3,10-13]$.

A lot of data suggest a possible involvement of dopamine (DOP) in the modulation of synaptic transmission at hair cells - afferent fiber synapses of the mammalian cochlea. Employing the microiontophoretic technique, evidence was obtained that DOP had a specific biological effect on afferent synaptic transmission in the cochlea of mammals [14, 15]. Excitatory action of L-Glu agonists could be depressed by coadministration with $\mathrm{D}_{1}$ and $\mathrm{D}_{2}$ agonists in a dose-dependent manner. The action of DOP and its agonists on the chemically induced activity of afferent nerve fibers could be blocked by the $\mathrm{D}_{1}$ and $\mathrm{D}_{2}$ antagonists. Electrophysiological data from piribedil, a do- paminergic $\mathrm{D}_{2} / \mathrm{D}_{3}$ agonist, clearly demonstrated the modulatory action of this substance on radial afferent dendrites [16]. Moreover, this agonist was shown to play an immediate protective role in the prevention of dendrite damage under pathophysiological conditions resulting from an excitotoxic effect from L-Glu during acoustic trauma or ischemia.

The results of functional studies were consistent with the findings of immunohistochemical, ultrastructural, neurochemical and immunoelectron microscopic experiments. These studies showed that the lateral efferent system of the cochlea contains and uses DOP as a neurotransmitter/neuromodulator [3, 17-22]. Taken together, most of the data for the lateral olivocochlear efferent system suggest that DOP functions as a lateral efferent neurotransmitter/neuromodulator and controls the afferent synaptic transmission between hair cells and primary dendrites.

The present study was undertaken to investigate the effect of DOP on resting and chemically induced afferent activity of the vestibular nerve and to determine the DOP receptor subtypes responsible for this effect.

\section{Materials and Methods}

Experiments were performed on adult frogs (Rana temporaria, approx. body weight: $20 \mathrm{~g}$ ). Each frog was anesthetized by immersion in $0.1 \%$ MS 222 (3-aminobenxoic acid ethyl ester) until all signs of breathing activity ceased. They were then decapitated and the bone containing the membranous labyrinth was excised. The experimental procedure was approved by the Pavlov Institute of Physiology Animal Care and Use Committee. The isolated otic capsule (hereafter termed the preparation) was transferred to a recording chamber, where it was then opened to allow the test substances easier access to the synaptic site. The preparation was continuously perfused with Ringer solution of the following composition: $95 \mathrm{mM}$ of $\mathrm{NaCl}, 1.7 \mathrm{mM}$ of $\mathrm{KCl}, 3.4 \mathrm{mM}$ of $\mathrm{NaHCO}_{3}, 0.5 \mathrm{mM}$ of $\mathrm{NaH}_{2} \mathrm{PO}_{3} \cdot 2 \mathrm{H}_{2} \mathrm{O}, 1.8 \mathrm{mM}$ of $\mathrm{CaCl}_{2}, 0.6 \mathrm{mM}$ of $\mathrm{MgCl}_{2}$ and $2.5 \mathrm{mM}$ of glucose, and the $\mathrm{pH}$ was adjusted to 7.4. The flow rate was about $1 \mathrm{ml} / \mathrm{min}$. In experiments designed to access the postsynaptic action of the test substances, a high magnesium solution was obtained by substituting $11.4 \mathrm{mM}$ of $\mathrm{NaCl}$ and 1.8 $\mathrm{mM}$ of $\mathrm{CaCl}_{2}$ of the normal saline with $3.0 \mathrm{mM}$ of $\mathrm{MgCl}_{2}$ and 0.1 $\mathrm{mM}$ of $\mathrm{CaCl}_{2}$, respectively.

The compounds used were: L-Glu, DOP, NMDA (N-methylD-aspartate), AMPA (D,L- $\alpha$-amino-3-hydroxy-5-methyl-4-isoxazolepropionic acid), chloro-APB hydrobromide (CAPB, $\mathrm{D}_{1}$ agonist) and quinerolane (QUI, $\mathrm{D}_{2}$ agonist; all compounds were from Sigma). Drugs were dissolved in the normal solution and the $\mathrm{pH}$ was adjusted when necessary. Test solutions were applied externally by switching a 6 -way stopcock, which substituted solutions.

Multiunit recording of action potentials from semicircular ampulla posterior afferents in the isolated preparation was per- 


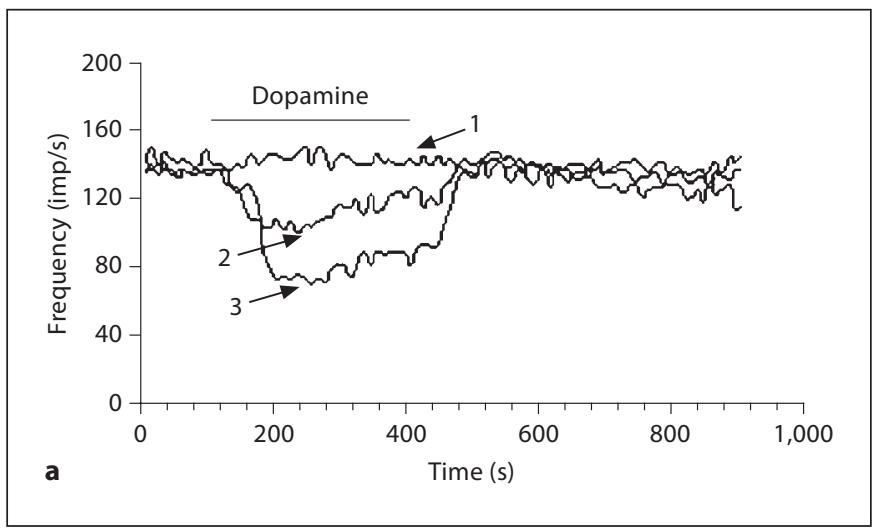

Fig. 2. Effects of DOP, the $D_{1}$ agonist and the $D_{2}$ agonist on the resting activity in vestibular afferent fibers of the frog. a Representative experiment employing different concentrations of DOP on the resting activity in afferent fibers of the semicircular canal nerve. The horizontal bar above the recordings indicates the duration of the application of the drug. Concentrations of DOP used are: (1) $10^{-5} \mathrm{M}$, (2) $10^{-4} \mathrm{M}$ and (3) $10^{-3} \mathrm{M}$. Ordinate: spike frequen-

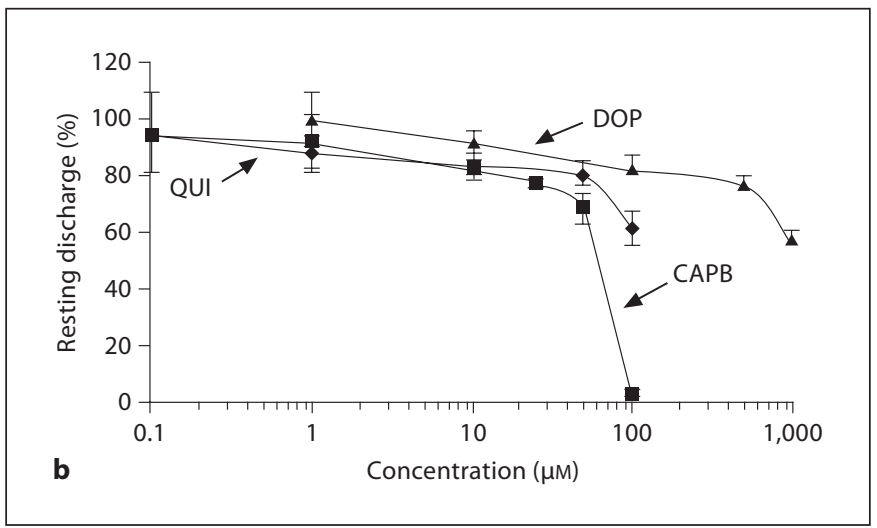

cy (imp/s); abscissa: time (s). b Dose-response relationships for DOP, the $\mathrm{D}_{1}$ agonist $\mathrm{CAPB}$ and the $\mathrm{D}_{2}$ agonist QUI. Drug effects were plotted as a suppression ratio of the resting discharge (\%). Each point with a bar represents the mean \pm SEM of at least 6 experiments. Ordinate: resting discharge (\%); abscissa: concentration $(\mu \mathrm{M})$.

\section{Results}

$300 \mu \mathrm{m}$ (fig. 1). The electrode was positioned with the tip at the cut end of the semicircular afferents by an electrode holder in a micromanipulator, and the whole nerve branch was sucked into the electrode. Test solutions were applied no earlier than $30 \mathrm{~min}$ after dissection of the preparation and after the beginning of perfusion with the normal solution when the resting discharge became stable. In the experiments, when several drugs were applied, an interval of at least $15 \mathrm{~min}$ permitted us to wash off the previous drug and to restore the control level of the resting activity. Spikes were electronically transformed into rectangular pulses of about 2-ms durations and were fed to a laboratory computer for continuous recording of the discharge frequency during the experiment. Neuronal activity was analyzed off-line by a computer as plots of spike frequency versus elapsed time. Spike frequency was determined over sequential 10 -second periods from the corresponding computer recordings.

The effects of the DOP agonists tested were calculated as the difference between the actual value of spike frequency measured during the maximum effect evoked by the drug and the average value of spike activity recorded over a 1-min interval prior to the drug application. These differences were then normalized as a percentage of change with respect to the control conditions. The frequency change under the combined action of the drugs was normalized as a percent of change with respect to the spike frequency value elicited by one of these drugs alone (control conditions). The data presented herein corresponded to the mean \pm SEM of 5-10 independent experiments. The differences between actual values of spike frequency were statistically analyzed using a paired t test and statistical significance was established at $\mathrm{p}<$ 0.05 .
The experiments were performed with DOP in concentrations between 0.001 and $1 \mathrm{mM}$, the $\mathrm{D}_{1}$ agonist (CAPB) in concentrations between 0.1 and $100 \mu \mathrm{M}$, and the $\mathrm{D}_{2}$ agonist (QUI) in concentrations between 0.1 and $100 \mu \mathrm{M}$. All free agonists tested consistently demonstrated an inhibitory response in afferent units. The initial frequency decrease was usually followed by a period of recovery; during continuous perfusion, the discharge frequency slowly returned to baseline (fig. 2a). Figure $2 b$ summarizes the data of all experiments in which the preparations were subjected to the actions of the DOP agonists. The effects of the various concentrations were plotted as a percentage suppression of the resting discharge. The effective concentration of DOP was as low as $0.1 \mathrm{mM}(\mathrm{n}=6 ; \mathrm{p}<0.05)$. Both CAPB and QUI did not considerably affect the magnitude of the response in the concentration range of $0.1-50 \mu \mathrm{M}$, being followed by a sharp increase of the inhibitory responses in concentrations between 50 and $100 \mu \mathrm{M}$. The excitatory potency of the bath-applied $\mathrm{D}_{1}$ agonist CAPB considerably exceeded that of the $\mathrm{D}_{2}$ agonist QUI. In 12 preparations tested in 2 sets of experiments, $100 \mu \mathrm{M}$ of CAPB and $100 \mu \mathrm{M}$ of QUI induced a decrease in firing frequency (mean: $3.5 \pm 1.2 \%$ and $61.5 \pm 6.2 \%$ of the control level, respectively; $n=6$ for each of the agonists). This effect was reversed by washing out the preparations with normal solution. 


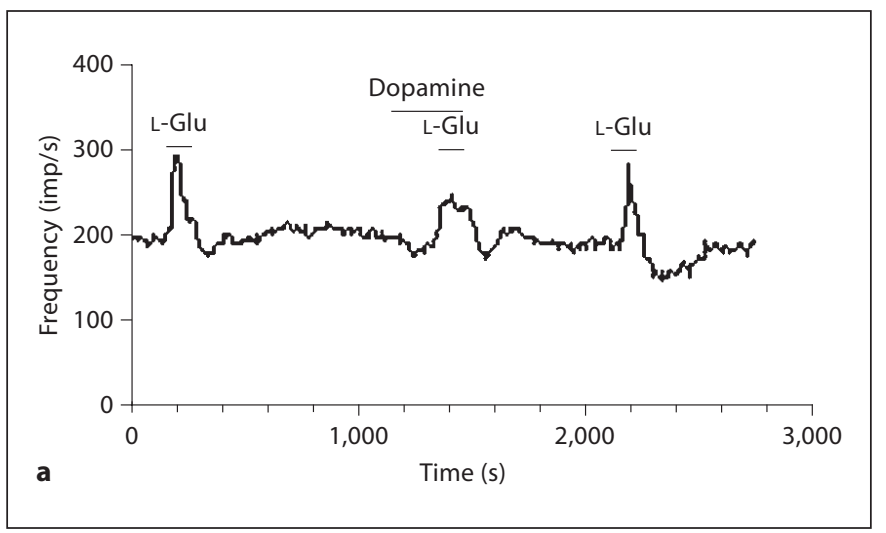

Fig. 3. Effects of DOP on excitation in afferent fibers due to L-Glu (a) and NMDA (b). Two experiments are shown with $0.1 \mathrm{mM}$ of L-Glu and $50 \mu \mathrm{M}$ of NMDA, which enhanced resting frequency. Then, normal solution was added, which stopped the effects of the L-Glu agonists. DOP (0.5 mM) decreased afferent activity. The ad-

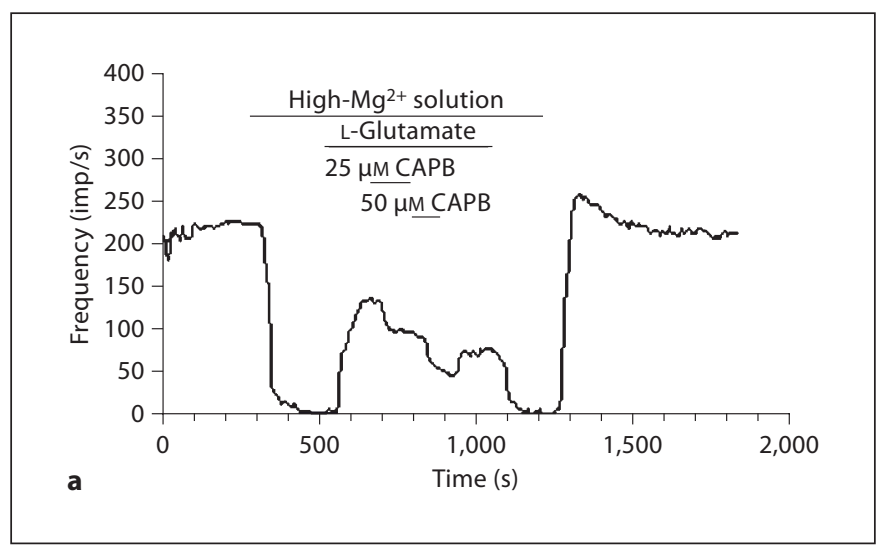

Fig. 4. Effects of CAPB and QUI on the postsynaptic responses evoked by L-Glu. High $\mathrm{Mg}^{+2}$ solution blocked neurotransmitter release and resting activity. The addition of $1 \mathrm{~mm}$ of L-Glu led to the reappearance of resting activity and a sustained level of resting discharge, probably due to the postsynaptic effect of L-Glu.

The modulatory action of DOP on glutamatergic synaptic transmission was tested in the experiments with a combined action of DOP and ionotropic L-Glu agonists. Figure 3 shows that the control application of $0.1 \mathrm{mM}$ of L-Glu (a) or $50 \mu \mathrm{M}$ of NMDA (b) caused a rise in resting frequency, which was restored after a wash-out period. During subsequent perfusion with $0.5 \mathrm{mM}$ of DOP, the resting discharge went down and the receptor displayed a sustained level of activity. The addition of $0.1 \mathrm{mM}$ of L-Glu, $1 \mu \mathrm{M}$ of AMPA (not shown) or $50 \mu \mathrm{M}$ of NMDA

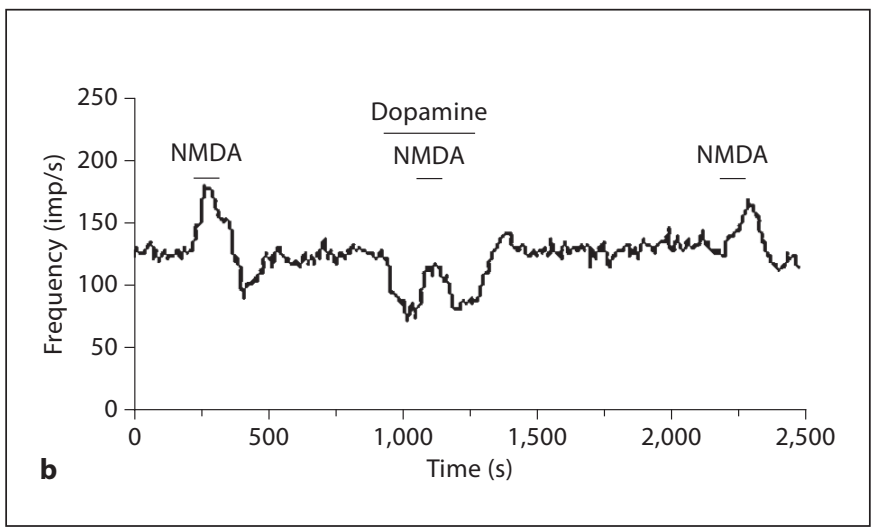

dition of $0.1 \mathrm{mM}$ of L-Glu or $50 \mu \mathrm{M}$ of NMDA to the solution containing DOP considerably reduced the excitatory action of amino acids. When normal solution was applied again, resting activity recovered as well as the frequency enhancing effect of L-Glu and NMDA. Ordinate: spike frequency (imp/s); abscissa: time (s).

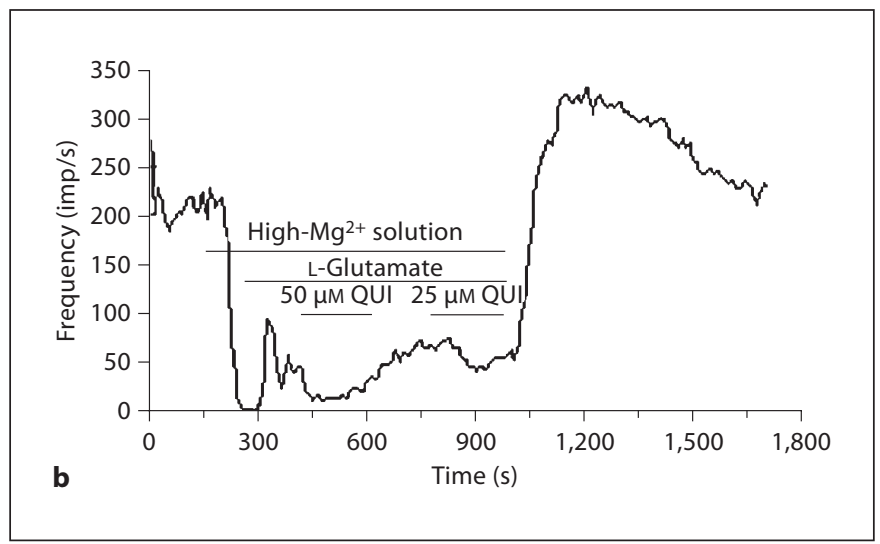

Subsequent perfusion with CAPB (a) or QUI (b) produced a concentration-dependent inhibition of the afferent discharge. Perfusion with normal solution restored the resting activity with a frequency similar to the initial frequency. Ordinate: spike frequency (imp/s); abscissa: time (s).

to the solution containing DOP induced a frequency increase, but the responses were considerably smaller compared to the control perfusion. DOP $(0.5 \mathrm{mM})$ antagonized responses induced by the application of L-Glu by $24.0 \pm 3.2 \%(n=5 ; p<0.05)$. Firing evoked by AMPA $(1 \mu \mathrm{M})$ or NMDA $(50 \mu \mathrm{M})$ could be depressed by the administration of $0.5 \mathrm{mM}$ of DOP by $64.5 \pm 11.2 \%(\mathrm{n}=6$; $\mathrm{p}<0.05)$ and $55.9 \pm 9.9 \%(\mathrm{n}=6 ; \mathrm{p}<0.05)$, respectively. At the end of recording, after the normal solution had restored the activity in afferent fibers, a control applica- 


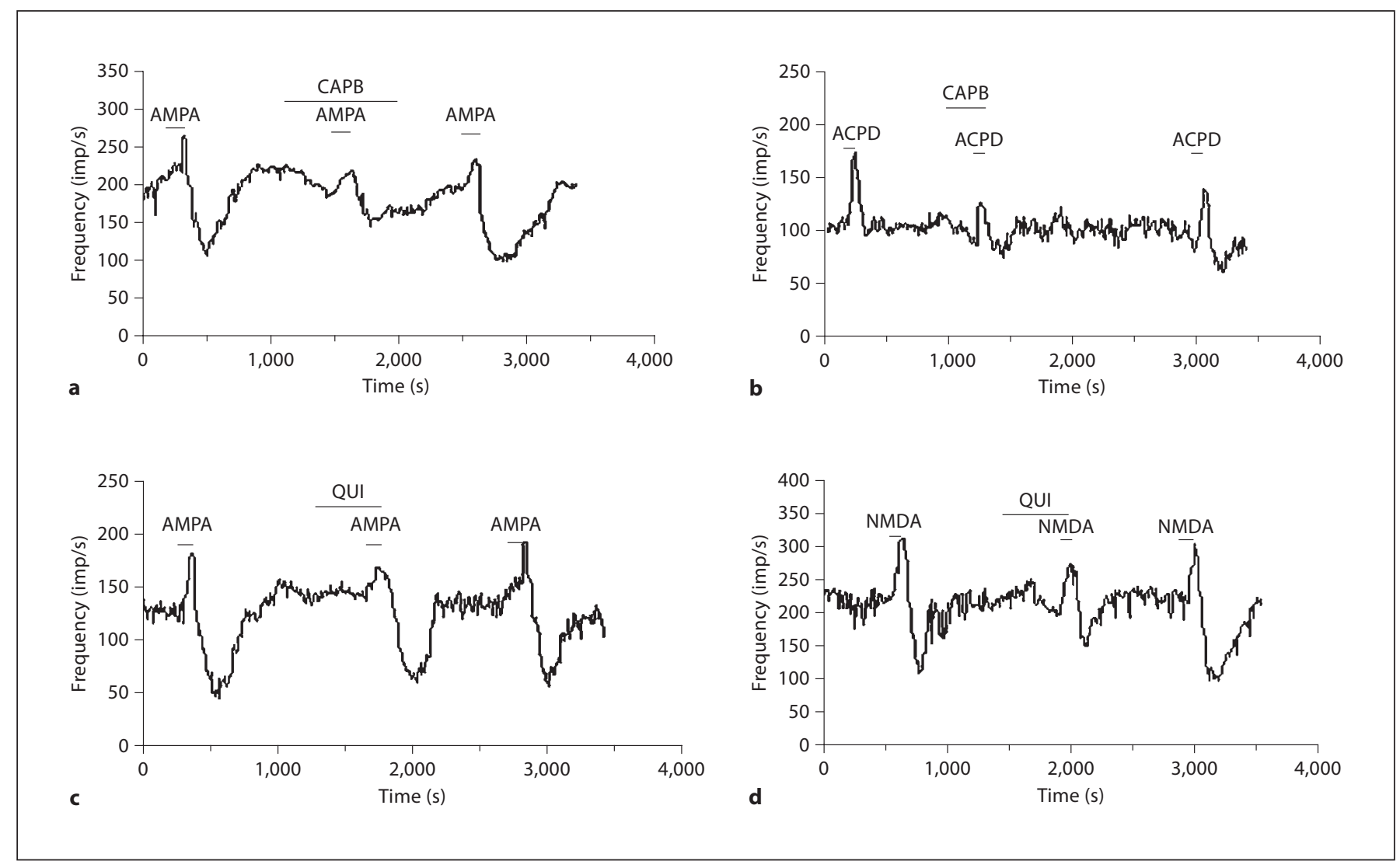

Fig. 5. Effects of the $\mathrm{D}_{1}$ agonist $\mathrm{CAPB}$ and the $\mathrm{D}_{2}$ agonist QUI on excitation in afferent fibers by L-Glu agonists. Representative recordings showing the effect of $100 \mu \mathrm{M}$ of CAPB on the responses evoked by $1 \mu \mathrm{M}$ of AMPA (a) and $300 \mu \mathrm{M}$ of ACPD (b), and the effect of $100 \mu \mathrm{M}$ of QUI on the responses evoked by $1 \mu \mathrm{M}$ of AMPA (c) and $50 \mu \mathrm{M}$ of NMDA (d) in the semicircular canal nerve. Ordinate: spike frequency (imp/s); abscissa: time (s). tion of L-Glu, AMPA and NMDA caused a rise in resting frequency.

To investigate a possible involvement of postsynaptic glutamate receptors as a site of action of DOP agonists, $0.1 \mathrm{mM}$ of L-Glu was employed. In these experiments, neuronal activity was first blocked with a high $\mathrm{Mg}^{2+}$ solution. The addition of L-Glu induced the facilitation of the afferent discharge even in the presence of $3 \mathrm{mM}$ of $\mathrm{Mg}^{2+}$ solution. This indicates that L-Glu acts postsynaptically. The subsequent addition of the $\mathrm{D}_{1}$ agonist CAPB (fig. 4a) or $\mathrm{D}_{2}$ agonist QUI (fig. $4 \mathrm{~b}$ ) under these conditions elicited a decrease in the firing rate in the afferent nerve terminals. Although we did not carry out any systematic quantitative investigations of the inhibitory potencies of these agonists in the wide concentration range in a high $\mathrm{Mg}^{2+}$ solution ( $\mathrm{n}=3$ at concentrations of 25 and $50 \mu \mathrm{M}$ in both series of experiments), the magnitude of the effect clearly depended on the concentration of the DOP ago- nists. The effects of the $\mathrm{D}_{1}$ and $\mathrm{D}_{2}$ agonists in these conditions were reversible.

To test for the interaction with the DOP agonists, the effects of the ionotropic L-Glu agonists AMPA (fig. 5a, c) and NMDA (fig. 5d), and the metabotropic L-Glu agonist ACPD (fig. 5b) were studied during a continuous application of CAPB or QUI. In these experiments, the preparation was first perfused with a solution containing one of the L-Glu agonists, and the effect observed was compared with the effects observed in the presence of the DOP agonists. As it is clearly seen, the addition of L-Glu agonists to the solution containing CAPB or QUI induced a frequency increase, but the responses were considerably smaller compared to the control perfusion of the corresponding agonists. To determine if real significant differences were obtained through the modification of AMPA, NMDA and ACPD responses to DOP agonists, a comparison of the means in the presence of CAPB and QUI 
Table 1. Percentage modification of AMPA, NMDA and ACPD by $100 \mu \mathrm{M}$ of the $\mathrm{D}_{1}$ dopamine agonist CAPB and $100 \mu \mathrm{M}$ of the $\mathrm{D}_{2}$ dopamine agonist QUI

\begin{tabular}{cllr}
\hline & Resting discharge & Control & $+5 \times 10^{-5}$ M CAPB \\
\hline $\mathrm{D}_{1}$ dopamine agonist CAPB & & & \\
$1 \mu \mathrm{M}$ of AMPA $(\mathrm{n}=5, \mathrm{p}<0.05)$ & 100 & $135.0 \pm 6.5$ & $44.4 \pm 14.2$ \\
$50 \mu \mathrm{M}$ of NMDA $(\mathrm{n}=4, \mathrm{p}<0.05)$ & 100 & $201.9 \pm 23.9$ & $122.3 \pm 14.2$ \\
$300 \mu \mathrm{M}$ of ACPD $(\mathrm{n}=5, \mathrm{p}<0.05)$ & 100 & $139.4 \pm 7.0$ & $70.4 \pm 16.2$ \\
\hline & Resting discharge & Control & $+5 \times 10^{-5}$ M QUI \\
\hline $\mathrm{D}_{2}$ dopamine agonist QUI & & & \\
$1 \mu \mathrm{M}$ of AMPA $(\mathrm{n}=4, \mathrm{p}<0.05)$ & 100 & $136.3 \pm 8.3$ & $101.2 \pm 12.2$ \\
$50 \mu \mathrm{M}$ of NMDA $(\mathrm{n}=5, \mathrm{p}<0.05)$ & 100 & $155.8 \pm 16.2$ & $95.7 \pm 16.4$ \\
$300 \mu \mathrm{M}$ of ACPD $(\mathrm{n}=4, \mathrm{p}<0.05)$ & 100 & $128.3 \pm 15.2$ & $84.3 \pm 7.9$ \\
\hline
\end{tabular}

with the control discharge rate was performed. The respective decrement of the responses to L-Glu agonists by perfusion of the preparation with a solution with CAPB and QUI is depicted in table 1.

\section{Discussion}

Our results obtained by multiunit afferent activity and external perfusion demonstrated that DOP agonists exerted an inhibitory effect at the afferent hair cell synapses in the vestibular end organs of the frog. Sensitivity to DOP application varied considerably from preparation to preparation, but for most nerve branches, the threshold concentration of DOP was $0.1 \mathrm{mM}$. The $\mathrm{D}_{1}$ agonist $\mathrm{CAPB}$ and the $\mathrm{D}_{2}$ agonist QUI modulated the frequency of afferent discharge in the range of 50-100 $\mu \mathrm{M}$. Sensitivity of bath-applied DOP agonists obtained in the present experiments corresponds well to results reported on the inhibitory effects of DOP agonists in the mammalian cochlea [14-16]. Interestingly, the dose-response curves of DOP agonists were quite similar to each other in one important respect: without stimulation, the vestibular organs demonstrated ongoing transmitter release as shown by the continuous afferent discharge. A small change in the concentration of the drugs caused either no response or a near maximal decrease of impulse activity. Compared to the dose-response curves of other modulatory substances $[4,13,23]$, that of DOP agonists were much steeper; as a result, reductions in the firing rate under DOP agonists were highly concentration-dependent.

Dopaminergic Modulation of Synaptic Transmission
As the results of the present study indicate, DOP agonists may exert modulating effects on the excitatory action of L-Glu agonists. Actually, afferent activity in vestibular afferents evoked by L-Glu agonists AMPA, NMDA and ACPD can be modulated by DOP agonists in an inhibitory way. Moreover, these effects are unaffected by the blockade of transmitter release in high $\mathrm{Mg}^{2+}$ solutions, which could explain the postsynaptic nature of these responses. The inhibition of NMDA, AMPA and ACPD excitatory responses by DOP agonists suggests that DOP exerts inhibitory control over both ionotropic and metabotropic types of L-Glu receptors and that one possible site for DOP action is on the postsynaptic membrane of the hair cell, the afferent fiber synapse. This is in agreement with reports describing modulatory actions of DOP, $\mathrm{D}_{1}$ and $\mathrm{D}_{2}$ agonists in the mammalian cochlea [14$16,22]$.

The results obtained are consistent with the hypothesis that DOP has a specific biological effect on afferent synaptic transmission in the semicircular canals of the frog, and these effects are mediated by specific $D_{1}$ and $D_{2}$ membrane receptors. The above data demonstrate the existence of cellular mechanisms by which DOP can control the afferent discharge and modulate the effects of the neurotransmitter L-Glu. Our findings support and extend the evidence obtained on the mammalian cochlea showing that DOP is most likely released at the axodendritic synapses beneath the hair cells. The released DOP may act on $D_{1}$ and $D_{2}$ membrane receptors located on the postsynaptic membrane of the afferent nerve fibers; thus, it can alter the properties of postsynaptic receptors and the responsiveness of afferent fibers to L-Glu. As a conse- 
quence, the suggested physiological roles of the modulatory nature of DOP actions in the vestibular periphery, and in the cochlea as well, might be the negative control of glutamatergic synaptic transmission. Such a mechanism can be important in preventing excitotoxic injury in the afferent dendrites after an external application of $\mathrm{L}-\mathrm{Glu}$, acoustic trauma or inner ear ischemia.

\section{Acknowledgement}

This study was supported by grant No. 06-04-48280 from the Russian Foundation of Basic Research.

\section{References}

1 Akoev GN, Andrianov GN: Sensory Hair Cells: Synaptic Transmission. Berlin, Springer, 1993.

2 Bledsoe SC Jr, Bobbin RP, Puel JL: Neurotransmission in the inner ear; in Jahn F, Santos-Sacchi J (eds): Physiology of the Ear. New York, Raven Press, 1988, pp 385-406.

3 Guth PS, Perin P, Norris CH, Valli P: The vestibular hair cells: post-transductional signal processing. Prog Neurobiol 1998;54: 193-247.

4 Andrianov GN, Ryzhova IV: Opioid peptides as possible neuromodulators of the afferent synaptic transmission in the frog semicircular canal. Neuroscience 1999;93: 801-806.

5 Andrianov GN, Ryzhova IV: Effects of dalargin on excitation induced by L-glutamate agonists in the frog vestibular organs. Neuroreport 2000;11:183-186.

6 Andrianov GN, Ryzhova IV: Lack of evidence of an interaction between leu-enkephalin and muscarinic-like responses in the frog semicircular canal. Neurosignals 2003; 12:310-314.

7 Lioudyno MI, Verbitsky M, Holt JC, Elgoyhen AB, Guth PS: Morphine inhibits an alpha9-acetylcholine nicotinic receptor-mediated response by a mechanism which does not involve opioid receptors. Hear Res 2000; 149:167-177.
Soto E, Vega R: Actions of excitatory amino acid agonists and antagonists on the primary afferents of the vestibular system of the axolotl (Ambystoma mexicanum). Brain Res 1988;462:104-111.

-9 Demêmes D, Ryzhova IV: Ontogenesis of substance $\mathrm{P}$ in the rat peripheral vestibular system. Hear Res 1997;114:252-258.

10 Guth PS, Holt JC, Perin P, Athas G, Garcia M, Puri A, Zucca G, Botta L, Valli P: The metabotropic glutamate receptors of the vestibular organs. Hear Res 1998;125:154-162.

11 Hendricson AW, Guth PS: Transmitter release from Rana pipiens vestibular hair cells via mGluR: a role of intracellular $\mathrm{Ca}^{++}$release. Hear Res 2002;172:99-109.

12 Hendricson AW, Guth PS: Signal discrimination in the semicircular canals: a role for group I metabotropic glutamate receptors. Neuroreport 2002;13:1765-1768.

13 Andrianov GN, Puyal J, Raymond J, Ventéo S, Demêmes D, Ryzhova IV: Immunocytochemical and pharmacological characterization of metabotropic glutamate receptors of the vestibular end organs in the frog. Hear Res 2005;204:200-209.

14 Oestereicher E, Arnold W, Ehrenberger K, Felix D: Dopamine regulates the glutamatergic inner hair cell activity in guinea pigs. Hear Res 1997;107:46-52.

15 Ruel J, Nouvian R, d'Aldin C, Pujol R, Eybalin M, Puel JL: Dopamine inhibition of auditory nerve activity in the adult mammalian cochlea. Eur J Neurosci 2001;14:977-986.

-16 d'Aldin C, Puel JL, Leducq R, Crambes O, Eybalin M, Pujol R: Effects of dopaminergic agonists in the guinea pig cochlea. Hear Res 1995;90:202-211.
17 Gil-Loyzaga P, Parés-Herbute N: HPLC detection of dopamine and noradrenaline in the cochlea of adult and developing rats. Brain Res Dev Brain Res 1989;48:157-160.

18 Gil-Loyzaga P, Fernández-Mateos P, Vicente-Torres MA, Remezal M, Cousillas H, Arce A, Esquifino A: Effects of noise stimulation on cochlear dopamine metabolism. Brain Res 1993;623:177-180.

19 Gil-Loyzaga P, Vicente-Torres A, FernandezMateos P, Arce A, Esquifino A: Piribedil affects dopamine turnover in cochleas stimulated by white noise. Hear Res 1994;79: 178-182.

20 Gáborján A, Lendvai B, Vizi ES: Neurochemical evidence of dopamine release by lateral olivocochlear efferents and its presynaptic modulation in guinea-pig cochlea. Neuroscience 1999;90:131-138.

21 Eybalin M: Neurotransmitters and neuromodulators of the mammalian cochlea. Physiol Rev 1993;73:309-372.

22 Ruel J, Wang J, Rebillard G, Eybalin M, Lloyd R, Pujol R, Puel JL: Physiology, pharmacology and plasticity at the inner hair cell synaptic complex. Hear Res 2007;227:19-27.

23 Andrianov GN, Nozdrachev AD, Ryzhova IV: The role of defensins in the excitability of the peripheral vestibular system in the frog: evidence for the presence of communication between the immune and nervous systems. Hearing Res 2007;230:1-8. 